Artikel Penelitian

\title{
Identifikasi Senyawa Kuersetin dari Fraksi Etil Asetat Ekstrak Daun Alpukat (Persea americana Mill.)
}

\author{
Elly Rustanti ${ }^{*}$, Qurrotu A'yunin Lathifah²
}

${ }^{1}$ Sekolah Tinggi Ilmu Kesehatan Husada, Jombang, Indonesia, 61481

2Sekolah Tinggi Ilmu Kesehatan Hutama Abdi Husada, Tulungagung, Indonesia, 66224

\section{INFO ARTIKEL}

\section{Riwayat Artikel}

Direvisi 16 September 2018

Diterima 9 Desember 2018

Tersedia online 30 Desember 2018

* Email penulis korespondensi: eilrose1211.er@gmail.com

\section{ABSTRAK}

Avocado leaves (Persea americana Mill.) have many benefits in our health because the leaves contain many secondary metabolites. One of the secondary metabolites in avocado leaves is quercetin. Quercetin is the largest compound of the flavonols group in which percentage of quercetin and its glycosides is 60$75 \%$ of total flavonoids. The purpose of this study was to isolate quercetin compounds from ethyl acetate fraction of ethanol extract of avocado leaves and to determine the presence of quercetin compounds in the avocado leaves. The leaves were extracted by maceration using $95 \%$ ethanol and fractionated with ethyl acetate. Identification of quercetin compounds using liquid chromatography-mass spectrometry (LC-MS). The results of this study indicated that avocado leaf extract contained quercetin compounds with a retention time of 5.83 minutes with molecular weight $\mathrm{m} / \mathrm{z}=300.50-301.50[\mathrm{M}-\mathrm{H}]^{+}$.

Keywords: Avocado leaves, quercetin, LC-MS

Daun alpukat (Persea americana Mill.) banyak memiliki kegunaan dalam kesehatan karena mengandung banyak metabolit sekunder. Salah satu metabolit sekunder yang terkandung dalam daun alpukat adalah kuersetin. Kuersetin adalah senyawa kelompok flavonol terbesar yang mana kuersetin dan glikosidanya berada dalam jumlah sekitar $60-75 \%$ dari flavonoid. Tujuan dari penelitian ini adalah untuk mengisolasi senyawa kuersetin dari fraksi etil asetat dari ekstrak etanol daun alpukat dan untuk mengetahui adanya senyawa kuersetin dalam daun alpukat. Daun alpukat diekstraksi dengan metode maserasi menggunakan pelarut etanol 95\% dan difraksinasi dengan etil asetat. Identifikasi senyawa kuersetin dengan menggunakan kromatografi cairspektrometri massa (KC-SM). Hasil dari penelitian ini menunjukkan bahwa dalam ekstrak daun alpukat mengandung senyawa kuersetin dengan waktu retensi 5,83 menit dengan berat molekul $\mathrm{m} / \mathrm{z}=300,50-301,50[\mathrm{M}-\mathrm{H}]^{+}$.

Kata kunci: Daun alpukat, kuersetin, KC-SM 


\section{Pendahuluan}

Indonesia terkenal dengan kekayaan alam yang memiliki berbagai jenis tumbuhan yang berkhasiat sebagai obat. Obat tradisional telah dikenal dan digunakan secara turun-temurun oleh masyarakat Indonesia. Pemanfaatan obat tradisional pada umumnya lebih diutamakan untuk menjaga kesehatan, meskipun pemanfaatannya ada pula yang ditujukan sebagai pengobatan suatu penyakit.

Daun alpukat (Persea americana Mill.) merupakan daun yang memiliki banyak kegunaan dalam kesehatan karena mengandung zat fitokimia. Hasil penapisan fitokimia yang telah dilakukan Putri dkk. [1] menyatakan bahwa daun alpukat mengandung senyawa flavonoid, alkaloid, tanin, saponin dan steroid. Adapun hasil skrining fitokimia yang dilakukan Sentat \& Permatasari [2] menyatakan bahwa ekstrak daun alpukat memiliki kandungan senyawa kimia alkaloid, flavonoid, saponin dan tanin.

Kuersetin (quercetin) adalah salah satu zat aktif golongan flavonoid yang memiliki aktivitas biologis yang kuat. Apabila vitamin C mempunyai aktivitas antioksidan 1, maka kuersetin memiliki aktivitas antioksidan 4,7 [3]. Flavonoid merupakan sekelompok besar antioksidan bernama polifenol yang terdiri atas antosianidin, biflavon, katekin, flavanon, flavon, dan flavonol. Kuersetin termasuk dalam senyawaan flavonol. Kuersetin adalah senyawa kelompok flavonol terbesar dengan kandungan kuersetin dan glikosidanya berada dalam jumlah sekitar 60-75\% dari flavonoid [4].

Kuersetin dipercaya dapat melindungi tubuh dari beberapa jenis penyakit degeneratif dengan cara mencegah terjadinya proses peroksidasi lemak. Kuersetin memperlihatkan kemampuan mencegah proses oksidasi dari Low Density Lipoproteins (LDL) dengan cara menangkap radikal bebas dan mengkelat ion logam transisi [5]. Aktivifitas farmakologi flavonoid khususnya senyawa kuersetin yang potensial menimbulkan keinginan peneliti untuk mengetahui kandungan kuersetin yang terdapat dalam ekstrak daun alpukat dengan menggunakan metode LC-MS (liquid chromatography-mass spectrometry).

\section{Bahan dan Metode}

\subsection{Bahan}

Bahan utama yang digunakan adalah daun alpukat. Bahan kimia yang digunakan dalam penelitian ini adalah etanol 95\%, kloroform, etil asetat, asam sulfat pekat, asam asetat anhidrat, kolesterol standar, asam klorida, natrium bikarbonat, akuades, kertas saring, dan aluminium foil.

\subsection{Preparasi Sampel dan Isolasi Senyawa Kuersetin}

Daun alpukat dicuci dengan air mengalir dan dikeringanginkan kemudian dihaluskan dengan blender. Sampel daun alpukat yang telah dipreparasi sebanyak 400 gram ditambah $4 \mathrm{~L}$ etanol $95 \%$ dan didiamkan dalam bejana tertutup selama 24 jam. Maserasi dilakukan tiga kali ulangan agar ekstraksi berlangsung sempurna. Hasil maserasi berupa ekstrak etanol daun alpukat, kemudian diuapkan dengan menggunakan rotary evaporator sehingga diperoleh ekstrak kental. Ekstrak dihidrolisis dengan asam klorida dan dinetralkan dengan natrium bikarbonat.

\subsection{Fraksinasi Ekstra Daun Alpukat}

Sampel hasil ekstrak difraksinasi dengan $200 \mathrm{~mL}$ etil asetat digojog selama 6 jam, lalu didiamkan selama 24 jam. Refraksinasi dilakukan sebanyak dua kali. Fraksi yang diperoleh diuapkan dengan menggunakan rotary evaporator hingga diperoleh fraksi etil asetat kental. Fraksi etil asetat selanjutnya diidentifikasi dengan menggunakan LC-MS.

\subsection{Identifikasi Senyawa Kuersetin Ekstrak Etanol Daun Alpukat}

Sampel ekstrak etanol daun alpukat hasil fraksinasi dianalisis menggunakan LC-MS untuk memperoleh data secara kualitatif. Dari hasil analisis data LC-MS akan didapatkan kromatogram berupa alur tinggi puncak dan akan didapatkan berat molekul dari senyawa yang terdapat dalam ekstrak etanol daun alpukat. Pengujian dilakukan dengan cara mengatur kondisi operasi alat LC-MS.

Analisis LC-MS dilakukan dengan menggunakan Mariner Biospectrometry dilengkapi dengan pompa biner. HPLC dihubungkan dengan spektrometer massa Q-TOF dilengkapi dengan sumber electrospray ionization (ESI). Mode extracted ion chromatogram (EIC) dari $\mathrm{m} / \mathrm{z} 100-1200$ dilakukan dengan suhu $140^{\circ} \mathrm{C}$. Kolom HPLC yang digunakan untuk

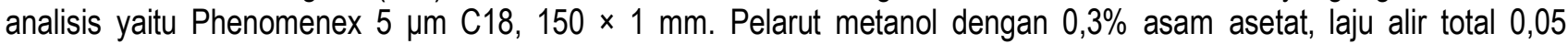
$\mathrm{mL} / \mathrm{menit}$ dan untuk menjalankan pelarut digunakan metode elusi isokratik. 


\section{Hasil dan Pembahasan}

\subsection{Preparasi Sampel}

Daun alpukat dicuci dengan air mengalir untuk menghilangkan debu dan kotoran yang melekat pada daun. Daun tersebut dikeringanginkan selama 2 jam di tempat yang terlindung dari paparan sinar matahari langsung. Pengeringan bertujuan untuk menurunkan kadar air, memudahkan pengolahan, dan memperlama penyimpanan [6]. Daun dihaluskan menggunakan blender dan diperoleh sampel halus sebanyak 400 gram untuk dilakukan ekstraksi. Penghalusan dengan blender bertujuan untuk memperkecil ukuran partikel sampel sehingga memperluas kontak permukaan antara cairan penyari dan bahan aktif yang terkandung dalam tanaman sehingga proses ekstraksi dapat berjalan dengan lebih maksimal. Sampel daun alpukat ditunjukkan pada Gambar 1.
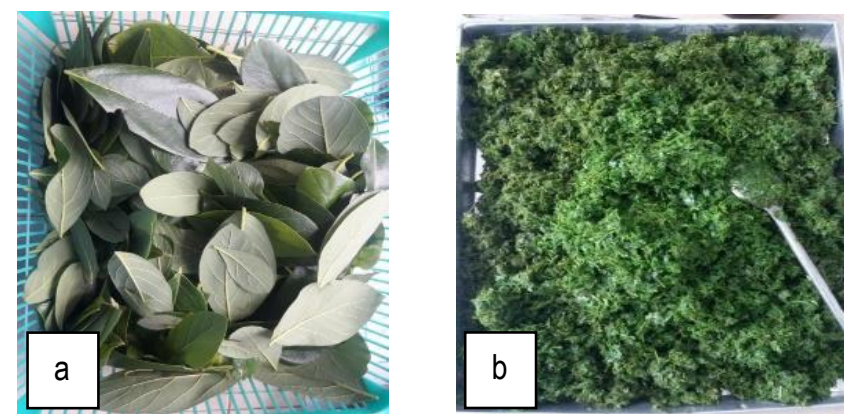

Gambar 1. Sampel daun alpukat (a) hasil pengeringan, dan (b) hasil penyerbukan

\subsection{Isolasi Senyawa Kuersetin dari Fraksi Etil Asetat Ekstrak Etanol Daun Alpukat}

Ekstraksi daun alpukat dilakukan dengan metode maserasi atau perendaman menggunakan pelarut etanol $95 \%$ (Gambar 2). Etanol dapat merusak dinding sel pada sampel sehingga senyawa yang bersifat polar dapat terlarut dalam etanol. Selama proses maserasi terjadi proses difusi. Metode maserasi dipilih karena cara pengerjaan dan peralatan yang digunakan sederhana dan metode ini memaksimalkan kontak antara pelarut dan bahan serta dapat digunakan untuk zat yang tahan maupun tidak tahan pemanasan [7]. Daun alpukat sebanyak 400 gram diekstraksi menggunakan 4 $\mathrm{L}$ etanol 95\% dengan cara direndam selama 24 jam sambil sesekali diaduk. Proses ini dilakukan tiga kali pengulangan untuk mendapatkan hasil ekstraksi yang maksimal.
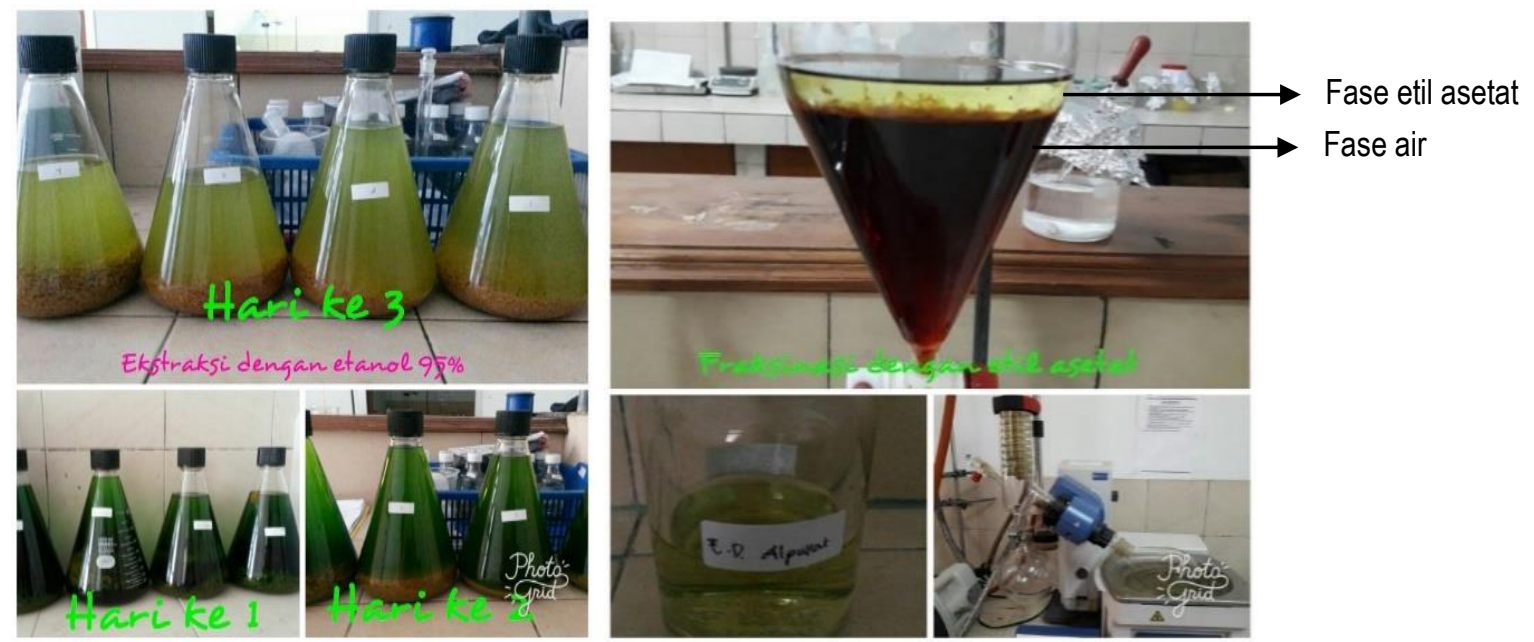

Gambar 2. Ekstraksi dengan etanol 95\% dan fraksinasi dengan etil asetat

Hasil maserasi disaring dan dipekatkan dengan menggunakan vaccum rotary evaporator pada suhu $45^{\circ} \mathrm{C}$ untuk menghindari kerusakan zat aktif akibat pengaruh suhu tinggi. Pada proses ini dihasilkan ekstrak kental. Ekstrak pekat selanjutnya dihidrolisis dengan asam klorida pada suhu ruang selama 2 jam dan dinetralkan dengan natrium bikarbonat bertujuan untuk memisahkan senyawa polar seperti kuersetin dari ekstrak pekat. Proses fraksinasi dilakukan dengan mengojog sampel menggunakan $200 \mathrm{~mL}$ etil asetat selama 6 jam, lalu didiamkan selama 24 jam. Refraksinasi berlangsung sebanyak dua kali. Fraksinasi dilakukan hingga fraksi etil asetat berwarna bening yang mengindikasikan bahwa semua senyawa semipolar yang terkandung di dalam sudah tertarik ke fraksi etil asetat. Fraksi yang diperoleh diuapkan dengan menggunakan rotary evaporator hingga diperoleh fraksi etil asetat kental. 


\subsection{Identifikasi Senyawa Kuersetin}

Fraksi etil asetat diidentifikasi dengan menggunakan LC-MS untuk mengetahui senyawa kuersetin berdasarkan berat molekulnya. Berdasarkan hasil identifikasi menggunakan LC-MS didapat bahwa dalam ekstrak daun alpukat mengandung senyawa kuersetin dengan waktu retensi 5,83 menit dengan $\mathrm{m} / \mathrm{z}=300,50-301,50[\mathrm{M}-\mathrm{H}]^{+}$. Hal ini sesuai dengan penelitian Harizon dkk. [8] yang menunjukkan bahwa senyawa kuersetin dari kulit batang Sonneratia alba (Lythraceae) berdasarkan spektrum UP-LC-MS/MS memiliki berat m/z 301,03 [M-H] $]^{+}$. Berdasarkan literatur, rumus molekul senyawa kuersetin adalah $\mathrm{C}_{15} \mathrm{H}_{10} \mathrm{O}_{7}$ dengan berat molekul $302,236 \mathrm{~mol} / \mathrm{g}$. Pada sampel fraksi etil asetat kuersetin didapatkan puncak spektrum $[\mathrm{M}-\mathrm{H}]^{+}$dengan nilai $\mathrm{m} / \mathrm{z} 301$ seperti pada standar kuersetin, tetapi dengan intensitas yang rendah (Gambar 3).

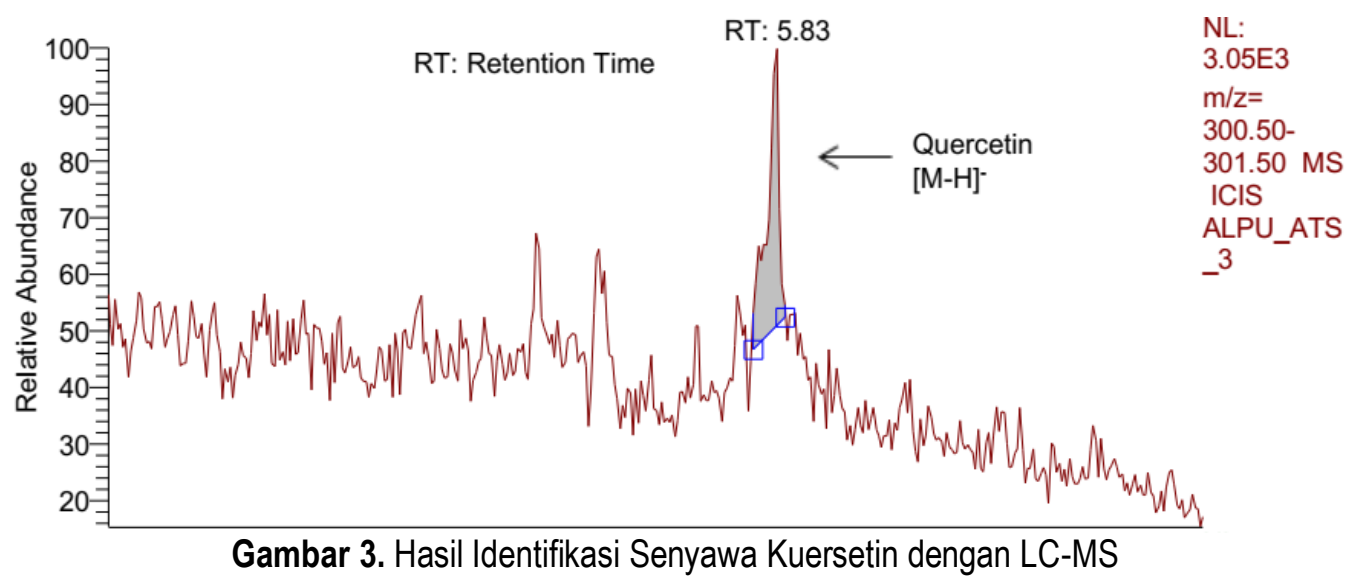

Pada penelitian Harizon dkk. [8] juga mengidentifikasi senyawa kuersetin dengan menggunakan UV, IR, dan NMR menunjukkan bahwa senyawa kuersetin diperoleh berupa padatan berwarna kuning; UV (MeOH): $\lambda$ maks $254 \mathrm{~nm}$

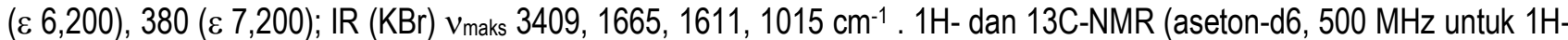
NMR dan $125 \mathrm{MHz}$ untuk 13C-NMR). Penelitian Fitrya [3] menunjukkan bahwa hasil isolasi flavonoid kuersetin dari tanaman benalu teh berupa serbuk amorf berwarna kuning dengan titik leleh $177-179{ }^{\circ} \mathrm{C}$. Analisis spektrum UV menunjukkan $\lambda_{\text {maks }}$ pita I $(348 \mathrm{~nm})$ dan pita II $(255 \mathrm{~nm})$. Pereaksi geser $\mathrm{NaOH}, \mathrm{NaOAc}, \mathrm{NaOAc/asam}$ borat, $\mathrm{AlCl}_{3}$ dan $\mathrm{AlCl}_{3} / \mathrm{HCl}$ menunjukkan bahwa senyawa flavonoid tersubstitusi pada 3,3',4',5,7 pentahidroksi flavon. Analisis spektrum IR menunjukkan adanya regang $\mathrm{OH}\left(3369 \mathrm{~cm}^{-1}\right)$, regang $\mathrm{C}-\mathrm{H}$ alifatik $\left(2956 \mathrm{~cm}^{-1}\right)$, regang $\mathrm{C}=\mathrm{O}\left(1658 \mathrm{~cm}^{-1}\right)$, regang $\mathrm{C}=\mathrm{C}$ $\left(1606 \mathrm{~cm}^{-1}\right)$ dan ulur C-O $\left(1271-1143 \mathrm{~cm}^{-1}\right)$. Berdasarkan analisis data spektrum UV dan IR menunjukkan senyawa hasil isolasi adalah flavonoid 3,3,4,5,7-pentahidroksi flavon atau kuersetin.

\section{Kesimpulan}

Berdasarkan hasil penelitian yang telah dilakukan dapat disimpulkan bahwa ekstrak etanol daun alpukat hasil fraksinasi dengan etil asetat mengandung senyawa kuersetin pada waktu retensi 5,83 menit dengan berat molekul $\mathrm{m} / \mathrm{z}$ sebesar 300,50-301,50 [M-H] $]^{+}$tetapi belum diketahui secara kuantitatif kandungan senyawa kuersetin yang terdapat dalam ekstrak etanol daun alpukat.

\section{Daftar Pustaka}

[1] E. P. K. Putri, B. Hamzah, \& N. Rahman, "Analisis Kualitatif Zat Bioaktif pada Ekstrak Daun Alpukat (Persea Americana Mill.) dan Uji Praklinis dalam Menurunkan Kadar Glukosa Darah pada Mencit (Mus musculus)," Jurnal Akademika Kimia, vol. 2, no. 3, pp. 119-127, 2013.

[2] T. Sentat, \& R. Permatasari, "Uji Aktivitas Ekstrak Etanol Daun Alpukat (Persea Americana Mill.) terhadap Penyembuhan Luka Bakar pada Punggung Mencit Putih Jantan (Mus Musculus)," Jurnal IImiah Manuntung Sains Farmasi dan Kesehatan, vol. 1, no. 2, pp. 100-106, 2015.

[3] Fitrya, "Flavonoid Kuersetin dari Tumbuhan Benalu Teh (Scurulla atropurpureea BL. Dans)," Jurnal Penelitian Sains, vol. 14, no. 4(C) 14408, pp. 33-37, 2011.

[4] D. A. Anggorowati, G. Priandini, \& Thufail, "Potensi Daun Alpukat (Persea Americana Mill.) Sebagai Minuman Teh Herbal yang Kaya Antioksidan," INDUSTRI Inovatif, vol. 6, no. 1, pp. 1-7, 2016.

[5] G. S. Kelly, "Quercetin. Monograph," Alternative Medicine Review, vol. 16, no. 2, pp. 172-194, 2011. 
[6] H. Karyati, A. B. Utomo, \& E. V. Mutiara, "Pengaruh Pemberian Ekstrak Etanol dan Isolat Flavonoid Daun Murbei (Morus alba L.) terhadap Penurunan Kadar Kolesterol secara in vitro," Skripsi, Sekolah Tinggi IImu Farmasi, Semarang, 2013.

[7] A. Z. Imani, "Uji Aktivitas Antijamur Ekstrak Etanol Daun Mangga Bacang (Mangifera foetida L.) terhadap Candida albicans secara in vitro," Jurnal Mahasiswa PSPD FK Universitas Tanjungpura, vol. 3, no. 1, 2015.

[8] Harizon, B. Pujiastuti, D. Kurnia, D. Sumiarsa, U. Supratman, \& Y. Shiono, "Kuersetin dan Kuersetin-3-O-Glukosida dari Kulit Batang Sonneratia alba (Lythraceae)," Jurnal Kimia VALENSI: Jurnal Penelitian dan Pengembangan IImu Kimia, vol. 1, no. 1, pp. 33-38, 2015. 